\title{
Mapeamento Geológico na Exploração Mineral com uso de SIG e Realidade Virtual: Estudos Metodológicos
} \author{
Methodological Studies \\ Allan Büchi ${ }^{1}$ \\ Tiago Amâncio Novo ${ }^{1}$ \\ Patrícia Moreira Procópio Calazans ${ }^{2}$ \\ José Carlos Sícoli Seoane ${ }^{2}$ \\ Bruce Napier ${ }^{3}$ \\ Luiz Henrique Guimarães Castiglione \\ Ricardo Pagung
}

Geological Mapping in Mineral Exploration using SIG and Virtual Reality:

Recebido em abril de 2018.

Aprovado em agosto de 2018.

\begin{abstract}
RESUMO
O mapeamento geológico, uma das atividades da exploração mineral, está associado a riscos e investimentos e é fundamental para a criação de valor na mineração. A metodologia de sua execução se orienta para o desenvolvimento de soluções que garantam a confiabilidade dos recursos e reservas. Das geotecnologias aplicadas ao processo, a que tem se mostrado mais decisiva é a dos SIG - Sistemas de Informações Geográficas, que viabiliza maior integração de dados e informações e maior objetividade na identificação de valor. Considerando também que os corpos minerais precisam ser apreendidos em toda a complexidade tridimensional de suas formas, a geovisualização se tornaria mais eficaz se ela se desse em três dimensões (3D), com a associação de imagens realísticas, configurando uma representação em realidade virtual - RV. A associação entre SIG e RV pode proporcionar um aperfeiçoamento às atividades de mapeamento geológico, na aquisição de dados e nas campanhas de campo e na análise, discussão e geovisualização dos resultados do processo. Neste sentido, o objetivo dos trabalhos aqui reportados é identificar as instâncias do processo que podem ser aprimoradas com a aplicação das geotecnologias. Este trabalho contemplou uma avaliação pragmática da exploração mineral e da pesquisa geológica, uma identificação das atividades passíveis de aprimoramento, no caso as relacionadas com o mapeamento geológico, e sua representação de resultados, que poderiam passar de $2 \mathrm{D}$ para $3 \mathrm{D}$, com aplicação da modelagem implícita.
\end{abstract}

\footnotetext{
${ }^{1}$ Programa de Pós-graduação em Geologia - IGC - UFMG, Brasil. E-mail: allanbuchi@gmail.com, 2Departamento de Geologia - UFRJ, Brasil. E-mail: cainho@geologia.ufri.br

${ }^{3}$ British Geological Survey - Keyworth - UK. E-mail: brn@bgs.ac.uk
} 
PALAVRAS-CHAVE: Mapeamento Geológico. Realidade Virtual. Geovisualização. SIG. Exploração Mineral.

\begin{abstract}
Geological Mapping, one of the mineral exploration activities, is associated with risks and investments and is vital to the creation of value in mining. Solutions, which guarantee the reliability of resources and reserves, are in constant development. GIS - Geographic Information Systems have proven to be one of the most decisive of the technologies involved in the process, which ensures the integration of data and information and greater objectivity in identifying value. Considering that ore bodies need to be considered in the entire three-dimensional complexity of their shapes, geovisualization would be more effective if it were conducted in three dimensions (3D) with the association of realistic images, providing a representation in virtual reality - VR. The association between GIS and VR will lead to a new benchmark in mineral exploration geological research activities, in the acquisition of field data and in the analysis, discussion and visualization of exploration results. As such, the objective of this article is to identify the parts of the process, which can be improved using a geotechnological approach, and includes a pragmatic assessment of mineral exploration, of the activities to be improved and the planning, providing an insight into the practical effects of such improvements, as the geological mapping, which could be changed from $2 \mathrm{D}$ to $3 \mathrm{D}$ the representation of the results, with implicit modeling.
\end{abstract}

KEYWORDS: Geological mapping. Virtual Reality. Geovisualization. GIS. Mining Exploration.

$$
* * *
$$

\title{
Introdução
}

As atividades relacionadas a pesquisa mineral, dependem de grandes investimentos, e consequentemente envolvem altos riscos, sendo fundamentais para a criação de valor nos empreendimentos relacionados, Calazans et al. (2016). As diretrizes metodológicas de sua execução se orientam para o desenvolvimento de soluções que garantam a confiabilidade da aferição quantitativa e qualitativa dos recursos e reservas. Um de seus objetivos principais se constitui pela busca de uma maior exatidão na modelagem dos corpos minerais de interesse, com a maior otimização possível de processos e de tempo. Neste contexto, se torna muito importante avaliar o uso das geotecnologias, ou seja, das tecnologias que permitem uma aquisição mais qualificada dos dados do espaço físico e uma visualização mais rica dos aspectos geoespaciais importantes ao processo de exploração mineral. 
Em termos das geotecnologias, a que tem se mostrado mais decisiva é a dos SIG - Sistemas de Informações Geográficas, que tem demonstrado viabilizar uma maior integração de dados e informações, uma maior objetividade na identificação de valor e análise, no que diz respeito à correlação entre os diversos parâmetros envolvidos no processo. Ao longo das duas últimas décadas, estes sistemas vêm possibilitando novos desenvolvimentos metodológicos da exploração mineral (Athey et al, 2008; Aarruda Junior et al, 2010; Whitmeyer et al, 2010; Napier, 2011; Terrington et al, 2015; Calazans et al, 2016; Jordan e Napier 2016), no caso o mapeamento geológico, mas sem alterar, no entanto, de forma expressiva, a questão da visualização dos resultados, que continuaram sendo realizadas e apresentadas em mapas bidimensionais (2D).

A partir da premissa anterior, constata-se que os resultados da atividade de mapeamento geológico (mapas e perfis), precisam ser compreendidos em toda a sua complexidade tridimensional (3D). Neste sentido, a geovizualização se torna essencial, já que se trata da relação dos 3 eixos espaciais no qual as informações foram organizadas, sendo a visualização uma indução ao pensamento visual, Meneguette, (2013), Figura 1. Em teoria o poder analítico do intérprete teria uma melhoria considerável, avaliando que a análise da superfície é um elemento importante, e se estendendo a subsuperfície, permitiria uma imersão mais qualitativa na análise do que uma imagem em $2 \mathrm{D}$. Neste sentido, a realidade virtual (RV) e os Sistemas de Informação Geográfica (SIG) se tornam ferramentas essenciais das atividades de aquisição e interpretação de dados, sendo executáveis em todas as etapas constituintes do mapeamento geológico, précampo, campo e pós-Campo. Esta sequência de atividades apresenta impactos positivos em relação as geotecnologias, com o aprimoramento do planejamento (pré-campo), em um ambiente com integração de dados multidisciplinares e visualização $3 \mathrm{D}$, mapeamento digital com dados integrados e precisão (campo). O pós-campo em ambiente RV permite uma 
intensa interpretação dos dados adquiridos in loco, e correlação com os dados terceiros, Westhead (2013).

Figura 1 - Representação do espaço 3D no contexto da Geovizualização

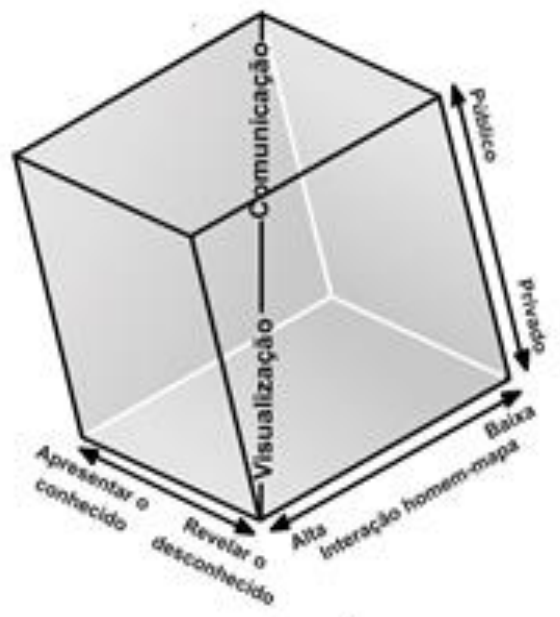

Fonte: MacEachren (1994) in Menguette (2014).

Estas considerações iniciais sinalizam que a associação entre o SIG e as geovisualizações em RV pode proporcionar um relevante aperfeiçoamento às atividades de exploração mineral, no caso especifico o mapeamento geológico, tanto na ponta da aquisição de dados e das campanhas exploratórias em campo, quanto na ponta da análise, discussão e geovisualização dos resultados intermediários e finais do processo.

Estes aprimoramentos poderiam ser meramente especulativos, entretanto observa-se o crescimento de pesquisas evidenciando os resultados aportados à atividade de mapeamento geológico. No caso, o British Geological Survey - BGS (Serviço Geológico Britânico), apresentou inúmeros aprimoramentos metodológicos a esta atividade com base no uso associado destas geotecnologias. O BGS vem desenvolvendo pesquisas aplicando e aprimorando sua metodologia denominada SIGMA - System for Integrated Geoscience Mapping (Jordan, 2009), nos trabalhos de mapeamento, visando a redução do tempo e do risco na execução de atividades, bem como, a otimização e o aperfeiçoamento na qualidade da coleta e interpretação dos 
dados. Ou seja, identificar as instâncias do processo de mapeamento geológico que podem ser aprimoradas com o uso das geotecnologias, com ênfase em SIG e RV. Pesquisas feitas com seres humanos deverão conter na seção Métodos, o número do protocolo e data de aprovação do Comitê de Ética.

\section{A Exploração Mineral e a Evolução Tecnológica}

A exploração mineral se fundamenta na execução de pesquisa cuja finalidade principal é a localização do minério de interesse para indústria. Neste sentido, envolve um conjunto grande de atividades, que se orientam praticamente todas no sentido da prospecção do corpo mineral de interesse, com o fito da determinação da sua extensão volumétrica, densidade, teor médio e de seu valor. Como atividade intelectual, a exploração mineral envolve um trabalho de equipe cujo resultado decorre da articulação de análises individuais de diversos geólogos. As análises individuais são inevitavelmente subjetivas, e o resultado final depende, em parte, dos esforços intelectuais de conciliação e integração destas. Os autores Coe et al. (2010) destacam que alguns dos principais desafios intelectuais da pesquisa geológica contemplam o processo de tomada de decisão sobre os dados que devem ser coletados e o registro dos mesmos. Neste contexto, as diversas perspectivas subjetivas devem se dar ao nível de dados básicos, ou seja, quanto mais consistentes e descritivos forem estes dados, na etapa de aquisição e discussão, maiores serão as chances de convergência do modelo e resultado. De uma perspectiva histórica mais ampla, acerca dos dados coletados e da produção de informações como resultado da pesquisa geológica, Whitmeyer (2010) observa que a apresentação dos produtos da pesquisa geológica na forma de mapas e de perfis basicamente se inicia na França com Cuvier e Brongniart (1808), e no Reino Unido, em 1815, com o mapa geológico da Inglaterra e de Gales, com Smith (Winchester, 2002), qual é um padrão que perdura até os dias atuais. 
A representação do conhecimento e dados geológicos, sintetizada em formas que permitam a percepção da sua distribuição espacial, entretanto, tem se transformado intensamente nas duas últimas décadas, desde a digitalização das informações geográficas até a utilização de plataformas 3D. Se desde Cuvier, Brongniart e Smith a informação geográfica se apresentava essencialmente da mesma forma, em mapas e perfis, hoje as possibilidades de apresentação geoinformacional se diversificaram muito, em formatos que incorporam diferentes formas de visualização, ou de geovisualização de dados e informações. Mapas, imagens, bases vetoriais, modelos digitais de elevação e outros elementos de constituição bidmensionais (2D) ou tridimensionais (3D) são exemplos de diferentes formatações dessas geoinformações (Figura 2). Neste contexto, Castiglione e Calazans (2011), observam que um conjunto de informações sobre a geologia de uma determinada área pode ser geograficamente consistente, se estiver contida numa base estruturada de informações, com uma representação, geoespacial e geoinformacional adequada à construção do conhecimento. A questão se sintetizaria então na pergunta: Como se deve constituir uma base de dados geográficos capaz de adequadamente contextualizar a construção do conhecimento sobre o fenômeno geológico de interesse, em especial no âmbito da exploração mineral? As respostas, no estágio atual das tecnologias, são muitas, em face dos desenvolvimentos decorrentes da aplicação massiva dos processos computacionais à produção e aquisição de dados por posicionamento global por satélites - GPS, do modelamento tridimensional pelo sensoriamento ativo - laser e radar e da farta produção de imagens digitais de altíssima resolução, por sensoriamento remoto. No trabalho de Athey et al. (2008), ao tratar da questão do mapeamento geológico, observam que uma das vantagens do ambiente digital na produção de geoinformações é decorrente da possibilidade dos geólogos envolvidos no mapeamento de intercambiar diariamente os dados de seus levantamentos de campo, viabilizando uma maior sinergia e articulação entre as análises. Esta integração de dados vem sendo viabilizada 
pela condição digital dos dados e informações e pelo compartilhamento de plataformas comuns de tratamento e processamento destes (Shufeldt 2012).

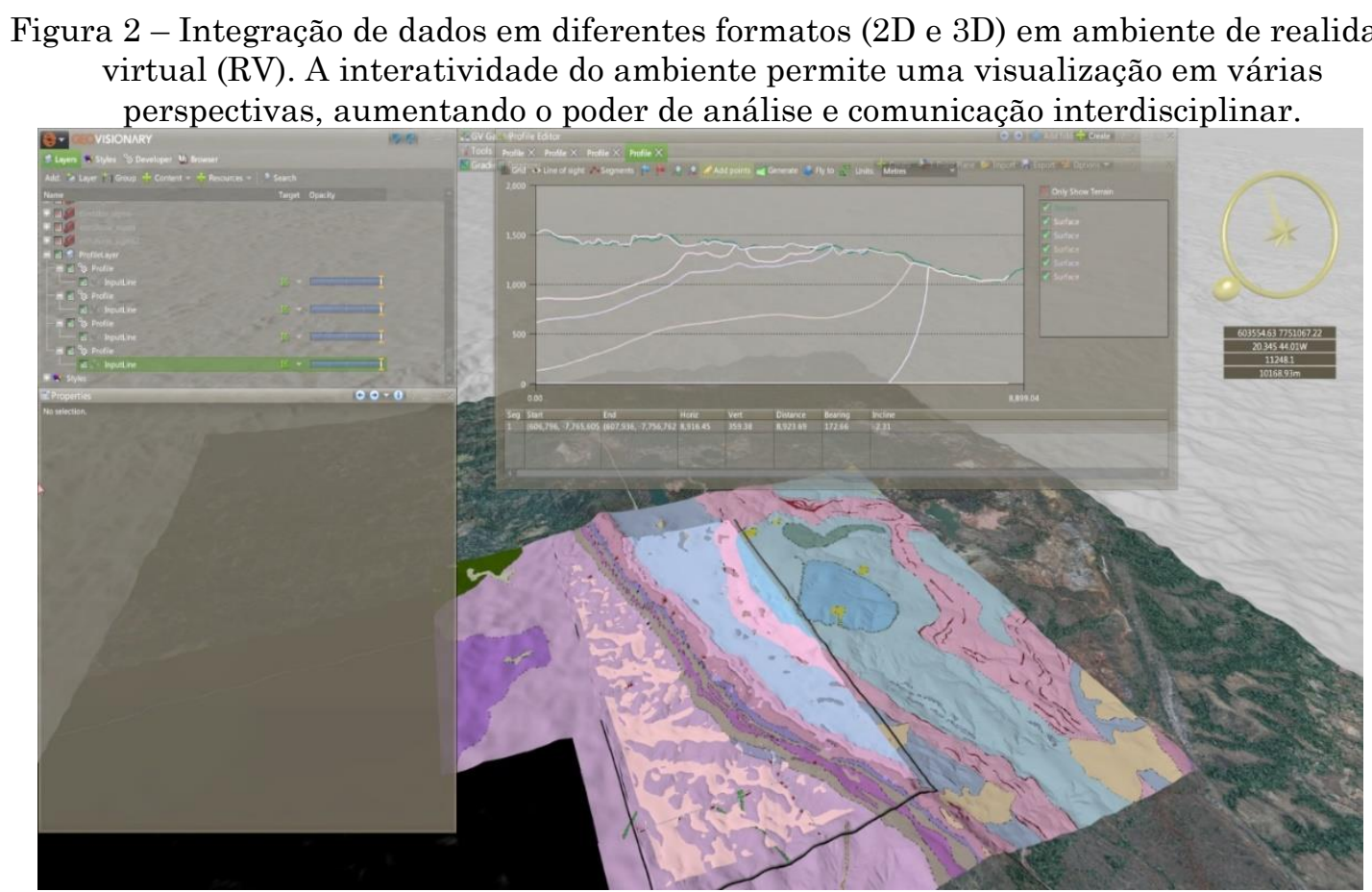

Fonte: Elaborado pelos Autores.

Estas transformações vêm se intensificando à medida que a tecnologia se desenvolve, ampliando ainda mais a visão de importância dos dados básicos e das informações produzidas ao longo do processo da exploração mineral. Desde as décadas de 1980 e 1990, aumentaram as aplicações digitais no tratamento de dados e na produção de geoinformações (Goetz et al, 1983; Bonham-Carter, 1994, Guimarães Filho, 1994) com o crescimento das chamadas geotecnologias, ou seja, das tecnologias especialmente orientadas para a produção de dados geográficos e geoinformações. Nesta época, já se vislumbrava os aprimoramentos que estas geotecnologias poderiam aportar a pesquisa geológica. Em 1994, quando os sistemas para tratamento da informação geoespacial ainda eram uma novidade em desenvolvimento, com aplicação ainda muito incipiente nos ambientes de trabalho, Guimarães Filho (1994) já observava que dados e informações de qualidade são indispensáveis ao sucesso do empreendimento exploratório, diminuindo a margem de erro na 
avaliação e permitindo que o geólogo tenha mais assertividade na avaliação do potencial metalogenético de uma área. O autor destaca ainda que a qualidade dos dados e o processamento decorrente para geração das geoinformações de interesse precisam se dar segundo sistemas que organizem e integrem os dados e permitam a produção sistêmica de informações, ao longo do processo. Esta visão, ao longo das últimas décadas, evidencia não apenas o papel estruturante e decisivo dos dados e informações como também traz para o centro do processo exploratório o uso do SIG. Neste sentido, e considerando os argumentos anteriores acerca do compartilhamento de análises pelas equipes envolvidas na exploração, o SIG se coloca como uma ferramenta indispensável, desde a estruturação dos dados preexistentes até o resultado final da síntese analítica do processo, cumprindo ainda, durante o processo exploratório, o papel fundamental de integrador e articulador das diversas visões e análises produzidas, individualmente, por cada equipe envolvida no processo.

Estas mudanças metodológicas não ocorrem de forma idêntica nos processos da exploração mineral; como Whitmeyer (2010) observa, os avanços dos meios de transporte que apoiam as atividades de campo foram da montaria de animais aos veículos automotores, enquanto que a metodologia básica de aquisição e apresentação de dados de campo permanece basicamente a mesma. Este mesmo autor destaca que o mapeamento geológico permanece demandando inúmeras horas de trabalho de campo, na classificação, medição, catalogação e interpolação de unidades geológicas, nas mais variadas escalas de análise, o que de fato se constata ao analisar os procedimentos operacionais acadêmicos e profissionais das várias equipes de geólogos da exploração mineral. Neste caso, às possibilidades criadas pelas novas geotecnologias disponíveis, são inúmeras em questão da redução de tempo e melhorias na aquisição e interpretação de dados, entretanto o método tradicional e analítico se mantém em sua base. Ou seja, os aprimoramentos observados com o uso de geotecnologias são mais potencializações do que 
transformações, a metodologia se mantém em sua maneira clássica de atuação, mas com melhorias aplicadas aos processos dessa atividade.

No caso do SIG sua importância como sistema está na estruturação de dados e informações, Souza Filho e Crosta (2003). No caso dos estudos geológicos, este valor se reafirma, porque a maioria dos dados envolvidos tem natureza geoespacial. Neste sentido, a evolução das geotecnologias torna cada vez mais decisiva a tomada de posição sobre a formatação (imagética, vetorial, modelos digitais de terreno) e as especificações de exatidão (qualidade da representação) dos dados, inclusive na transformação metodológica da pesquisa mineral. Estas transformações demonstram que, o papel das informações geográficas na transmissão de conhecimento tem se tornado essencial, e que, portanto, uma avaliação criteriosa das especificações precisaria redefinir que soluções geotecnológicas adotar no suporte às pesquisas da exploração mineral. Faz sentido, portanto, analisar os mecanismos de aquisição, tratamento e representação de dados e a sua adequação aos trabalhos e estudos na pesquisa geológica. Há ainda que se considerar que as análises e planejamentos necessitam de bases de dados geográficos consistente que atenda as demandas de integração e acurácia das informações, para que a mesma possa ser utilizada de forma multidisciplinar e com representatividade e exatidão.

Diversos são os fatores que indicam um crescimento nas demandas de exatidão e representatividade. Os novos ambientes computacionais para os trabalhos de análise e planejamento, impulsionados pelo SIG estão viabilizando uma integração mais precisa de dados de diversas fontes, tornando exequíveis as análises mais apuradas. Estas análises, por sua vez, acabam por aumentar a demanda por dados de mais qualidade, exercendo influências no desenvolvimento na área das geotecnologias.

Em termos históricos, este processo de aprimoramento na produção de dados e informações mais qualificadas para reduzir a margem de incerteza do processo analítico, tem sido contínuo segundo Santos e Ribeiro Filho (1989). Estes autores observam ao tratar da evolução da exploração mineral ao longo 
do século passado, que os principais avanços no campo da geofísica se deram no período de 1945 a 1955, com a aeromagnetometria de campo total, a eletromagnetometria aérea, a espectrometria de raios gama e a polarização induzida. De uma forma geral, as evoluções dos equipamentos geofísicos tornaram a sua aplicação cada vez mais rentável. Os autores destacam ainda que, na década de 50, a utilização sistemática dos levantamentos aerogeofísicos se constituiu num dos fatores mais decisivos para impulso às atividades de investigação mineral, o mesmo ocorrendo nas duas últimas décadas com o aprimoramento de sensores e técnicas geofísicas, tais como gradiometria, GPR, sísmica (Braga et al. 2010). Os autores Siegel (1985), Santos e Ribeiro Filho (1989) observam que as principais tendências da exploração mineral, à época, davam conta de que a aplicação de técnicas exigiria "determinações mineralógicas quantitativas, análises dos constituintes maiores e menores das rochas, caracterização dos padrões de dispersão dos elementos em superfície e na rocha-mãe, registro de elementos multiespectrais em maior número de faixas etc.”. Siegel (1985) basicamente centra sua previsão na extensão da capacidade de investigação do geólogo através do chamado Sensoriamento Remoto. Esta, de fato, parece ser uma condição em que um aprimoramento ocorre, porque grande parte da capacidade da análise geológica atualmente, decorre do uso de extensores da capacidade (geotecnologias) de observar e avaliar os objetos de pesquisa. As técnicas de sensoriamento remoto têm sido muito importantes na exploração mineral, exemplificando a aerogeofisíca a qual rompe as barreiras naturais da observação geológica, (SOUZA FILHO e CRÓSTA, 2003; SEOANE et al, 2003; SANTOS et al, 2010).

Analisando comparativamente o uso de imagens de sensoriamento remoto nas análises geológicas, pode-se observar que a principal transformação que irá marcar e caracterizar as geoinformações começa a ganhar maior desenvoltura na década de 1920, com a fotogrametria (Goetz et al. 1983). Esta transformação caracteriza-se pela utilização de diversos tipos de imagens na geração de geoinformações, consolidando, na medida em que 
as geotecnologias se desenvolvem, uma tendência pela adoção de representações imagéticas em lugar daquelas de natureza semiótica (mapas). Nesse contexto, a representação de elementos de interesse a pesquisa mineral está cada vez mais dominada pelas imagens de altíssima resolução, tanto fotogramétricas digitais quanto satelitais e multi-espectrais.

As geotecnologias viabilizaram outro tipo de levantamento por sensoriamento remoto, que antes da década de 1990 era virtualmente impraticável, e que atualmente, torna-se cada vez mais importante à pesquisa geológica, trata-se do sensoriamento ativo, que diz respeito à modelagem volumétrica precisa de objetos tridimensionais. Este tipo de levantamento se tornou mais usual no século XXI com os equipamentos de varredura laser, produção de nuvens de pontos $2 \mathrm{D}$ e $3 \mathrm{D}$, capaz de caracterizar com precisão paisagens e formas, que antes apresentavam dificuldades de detalhamento e precisão pelas soluções antes existentes (Whitmeyer 2010).

Os ambientes de visualização e de análises mais precisas e de qualidades demandam dados qualificados em termos de exatidão e representatividade. Ou seja, nas atividades de produção de dados e geração de informação as geotecnologias existentes como a utilização de SIG em campo (mapeamento digital), ampliaram bastante as possibilidades de se produzir bases geoinformacionais de maior qualidade. Isso pode ser observado tanto no que tange à caracterização da geometria da representação (exatidão) quanto em termos dos aspectos representacionais. A representação da paisagem de interesse do analista melhorou muito com a utilização de imagens de altíssima resolução, com as representações vetoriais com intensa integração de dados e com as modelagens tridimensionais mais minuciosas, dentre outros produtos geoinformacionais.

O estudo amplo da exploração mineral, entretanto, não poderia prescindir de uma análise crítica das questões conceituais que subsidiam processos atuais, em especifico o mapeamento geológico. Para este fim, buscou-se empreender uma avaliação do fluxograma de tais atividades apresentado pelo BGS, que já havia consolidado novas tecnologias, de forma 
a que esta metodologia servisse como referência para a avaliação dos processos atuais relacionados ao mapeamento geológico (Jordan, 2009; Napier, 2015; Jordan e Napier 2016). Nesta análise, foram identificadas e avaliadas as possibilidades teóricas e práticas que a aplicação das geotecnologias de SIG e RV pode aportar na melhoria do mapeamento e produtos associados na pesquisa geológica. Com as análises práticas resultantes da revisão geral dos conceitos dos macroprocessos aos subprocessos, e com as análises conceituais observadas, foi estruturada uma avaliação teórico-prática das possibilidades de inserção das geotecnologias a pesquisa geológica, no sentido de aprimorar ou potencializar a geração de dados e informações. Estes ensaios de reestruturação foram levados à discussão multidisciplinar de sua viabilidade prática e sobre a pertinência das transformações propostas, instruindo um constante aprimoramento de sua estrutura conceitual. Os resultados são apresentados como uma proposta metodológica do processo de mapeamento, com a incorporação das mudanças que vêm sendo analisadas e redesenhadas, como observado em diversos trabalhos (JORDAN, 2009; JORDAN et al, 2009; WESTEAHEAD et al, 2012, 2013.; TERRINGTON et al, 2015; CALAZANS et al, 2016).

\section{Aplicação de SIG e RV no Mapeamento Geológico}

A análise crítica da metodologia atual da exploração mineral e a identificação de instâncias deste processo que poderiam ser aperfeiçoadas com a aplicação do estado da arte das geotecnologias pode ser o primeiro passo para o projeto de processos de exploração mais eficazes, no futuro.

Neste sentido, este estudo tem seu foco na exploração mineral, com ênfase no mapeamento geológico. A principal motivação vincula-se ao estudo das possibilidades de aperfeiçoamento dos resultados com a aplicação de modernas técnicas de aquisição, tratamento, geovisualização e interpretação de dados geológicos e dados auxiliares, em ambientes de SIG e RV. Não se trata apenas de uma melhora da geovisualização de dados, mas sim de uma 
transformação metodológica que poderá ser aportada por estas novas geotecnologias, aprimorando as análises geológicas, desde as etapas de coleta de dados para a avaliação inicial da área, reconhecimento geológico, mapeamento geológico e planejamento de sondagem, consequentemente, os resultados finais alcançados pelo processo, em especial na questão da avaliação de recursos e reservas. Há desdobramentos econômicos importantes nesta transformação, mas, apesar disso, há ainda alguma dificuldade em se trabalhar nesta linha, por conta dos vultosos investimentos que precisam ser feitos para a implantação de ambientes de RV, assim como no aporte de ferramentas de suporte às atividades de campo, como hardware (tais como notebooks, toughbooks e tablets) e softwares de última geração. Além disso, há também as questões de mudança cultural que se associam a todas as grandes transformações no cotidiano das atividades de pesquisa e exploração.

Com base nestas premissas e considerando o papel e a importância da exploração mineral na cadeia de valor da mineração, a elaboração da metodologia para identificar os aprimoramentos possíveis deve não apenas explorar possibilidades teóricas, mas, acima de tudo, experimentar na metodologia atual estes novos métodos, de forma a colocar efetivamente em prova estas transformações conceituais e operacionais. Por estas razões, analisou-se a metodologia convencional atualmente utilizada e, sobre esta articulação de atividades, foram idealizadas todas as aplicações possíveis do estado-da-arte das geotecnologias, de forma a potencializar o processo de mapeamento e a sua produção de resultados.

O principal desafio enfrentado na elaboração da metodologia está relacionado com a necessidade de comprovar as melhorias que a associação entre ambientes de SIG e RV pode trazer para a exploração mineral, no caso o mapeamento geológico, e qual instrumentação seria usada. A partir dessa premissa, foram destacadas a geotecnologias utilizadas pelo BGS, no caso software GeoVisionary e o aplicativo SIGMA Mobile, com integração em ambiente SIG. 
O GeoVisionary é um software que permite operacionalização ampla do processamento de dados, produção de geoinformações e geovisualização em contexto de realidade virtual. Permite a visualização grandes extensões geográficas, representadas por modelos digitais de elevação e imagens, permitindo a visualização 3D do território de interesse, articulada com camadas de informação SIG e dados de sub superfície. O sistema oferece também recursos de integração de dados de campo e de escritório, podendo ser utilizada para fotointerpretação, correlação de dados de diferentes áreas e integração dos mesmos. Em relação ao SIG, a solução adotada foi a plataforma ArcGIS, desenvolvida pela ESRI, quase que um padrão para geração de informações na pesquisa geológica. Para apoiar as atividades de campo, neste novo contexto de utilização ampla de soluções digitais, a op̧̧ão foi pelo software SIGMA Mobile, que é um aplicativo desenvolvido pelo BGS, através do conceito SIGMA. Desde sua concepção, como observado em Scheib (2005) foi idealizado como uma plataforma digital de coleta de dados em campo, através de equipamentos móveis, o que faz dele uma ferramenta muito adequada às operações de campo, especificamente voltadas para o mapeamento geológico.

Outro ponto de destaque, relacionado a necessidade de criação de representação 3D, seria a alocação de um software de modelamento, nas etapas do mapeamento geológico. A metodologia usual, consiste na representação de um modelo geológico, a partir do mapa geológico final e associado a outros de dados de aferição, no caso furos de sondagem, o que estaria fora do cronograma de atividade de campo. Para tanto observou-se a necessidade de utilizar um software que promovesse agilidade no modelamento geológico, neste caso a modelagem implícita, dinamiza este processo, e o programa Leapfrog, é o sistema que melhor representa a necessidade deste novo processo, como tratado em Cowan et al. (2004).

Esta solução metodológica foi estruturada de forma que permitisse uma avaliação mais precisa dos aprimoramentos possíveis, e se iniciaram pela 
divisão dos serviços em três etapas, que seguem uma ordem cronológica típica da atividade de mapeamento geológico.

\subsection{Pré-Campo}

Nesta etapa inicial, ocorre o planejamento e a interpretação da área de mapeamento definida. É montado um banco de dados SIG (shapes, imagens de alta resolução, mapas geológicos, modelo digital de terreno). Estes dados devem ser integrados no ambiente de Realidade Virtual através do software GeoVisionary, onde são analisados com técnicas de fotointerpretação e análise multidisciplinar de dados, para identificação de características geológicas e para estabelecimento das estratégias e atividades que nortearão as campanhas de campo (Figura 3).

Figura. 3 - Ambiente de realidade virtual, mostrando a integração de dados seções geológicas com modelo geofisíco, integrados no software GeoVisionary.

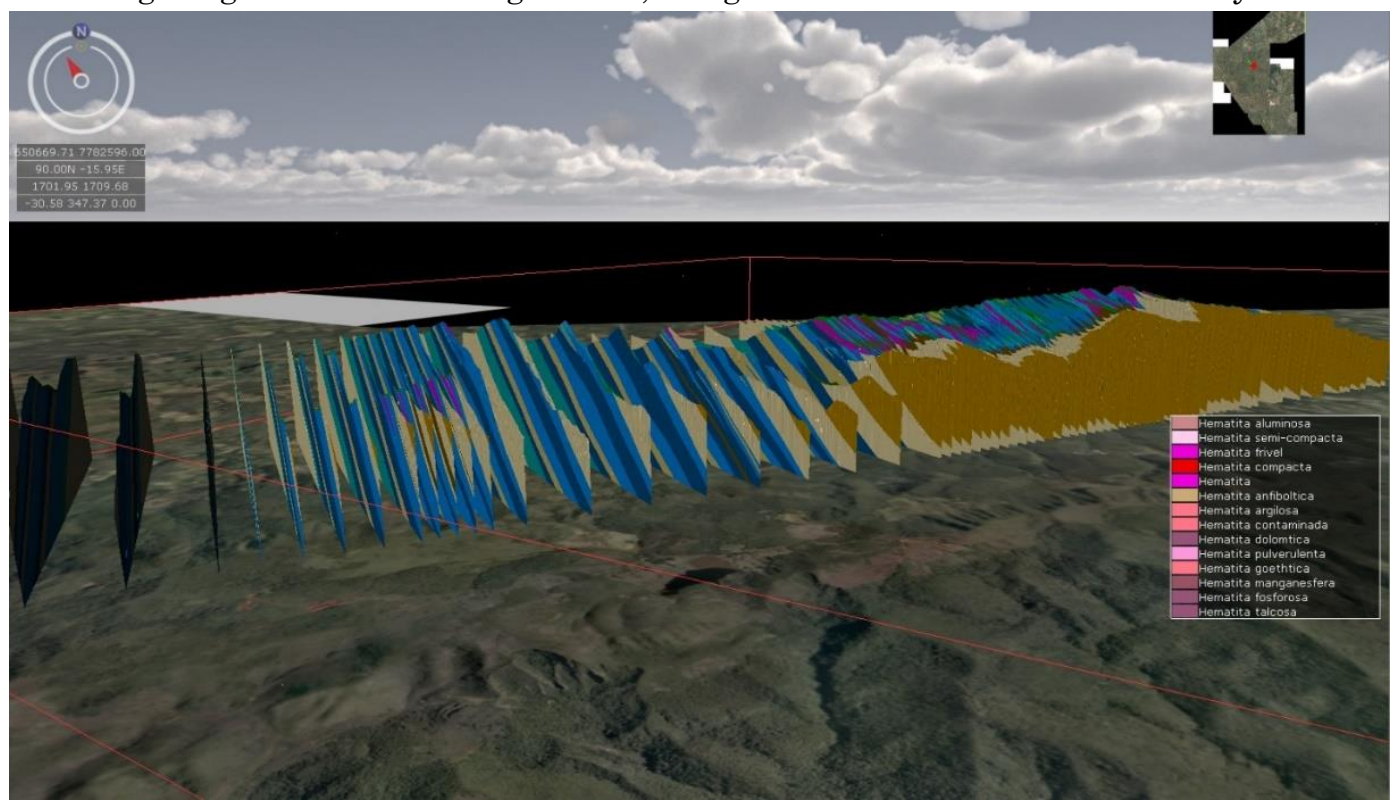

Fonte: Elaborado pelos Autores.

Os resultados destas análises (shapes, descrições e etc.) são exportados para uma plataforma de aquisição de dados em campo, constituída por um toughbook, processando o aplicativo SIGMA Mobile, observado em Calazans et al. (2016), este dispositivo apresenta um GPS integrado como apresentado 
na Figura 4. Nesta etapa, é gerado um modelo geológico 3D (no software Leapfrog) a partir de um banco de dados regional ou local. Este modelo será a base geológica tridimensional, para aferição e acurácia da foto interpretação e planejamento de campo. A importância desta etapa pode ser aferida pelo que estabelece por Wethead et al. (2013), ao reportar que a interpretação prévia no ambiente de RV permite aos geólogos a execução de levantamento virtual prévio, antes de efetivamente iniciar o levantamento real. Isso permite aos geólogos a construção preliminar de certo conhecimento do terreno e de seus aspectos geológicos mais aparentes, devido ao poder de simular em ambiente $\mathrm{RV}$, a realidade do campo, estabelecendo projeções de perfis, áreas de interesse, assim como possíveis afloramentos, tudo isso com mais exatidão, seja em conhecimento geológico até em relação a topografia do terreno. Estas premissas trazem mais confiança ao geólogo de campo, já que o conhecimento sobre a área de estudo, mesmo eu virtual, não deixa de corroborar com a realidade do campo, (WHITMEYER e DE PAOR 2014).

Figura 4 - Dados interpretados em ambiente de realidade virtual e exportados para o thougbook, para serem utilizados na etapa de campo; nota-se as linhas ponteadas demostrando o caminho percorrido pelo geólogo de campo, a partir do GPS integrado ao

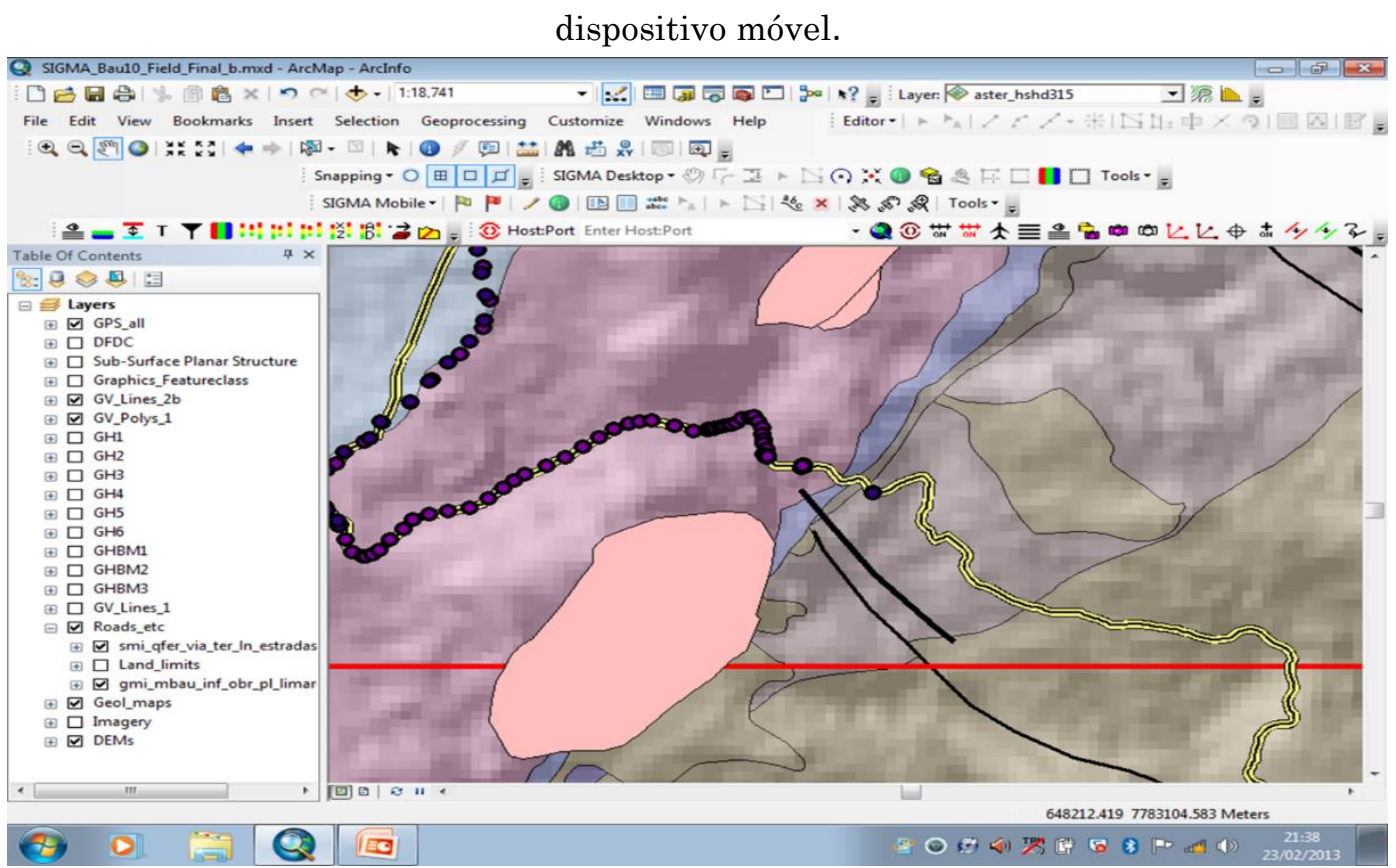

Fonte: Elaborado pelos Autores. 


\subsection{Campo}

No campo, a premissa mais importante considera que o profissional envolvido detém uma base de dados consistente para execução dos trabalhos e toda pré-interpretação efetuada na etapa anterior. Esta base de dados se encontra na plataforma ArcGIS, em um computador portátil (thoughbook) com câmera e receptor GPS integrados (Figura 05).

A aquisição de dados (pontos de descrição e interpretações) ocorre através do aplicativo SIGMA Mobile, que funciona como uma caderneta digital de campo, possibilitando o armazenamento de informações geológicas de forma organizada e precisa. Com a integração do SIGMA Mobile ao ambiente ArcGIS, torna-se possível a visualização em tempo real da localização na área de estudo, bem como a consulta e interpretação de informações digitais diversas, a qualquer instante em que elas se façam necessárias. Os produtos desta etapa seriam pontos geológicos organizados em uma estrutura de dados, shapes de interpretação e fotografias/imagens interpretadas, bem como mapas e relatórios de campo confeccionados durante o trabalho.

Figura 05 - Thougbooks, para mapeamento digital, com sistema SIG (ArcGIS e SIGMA Mobile).

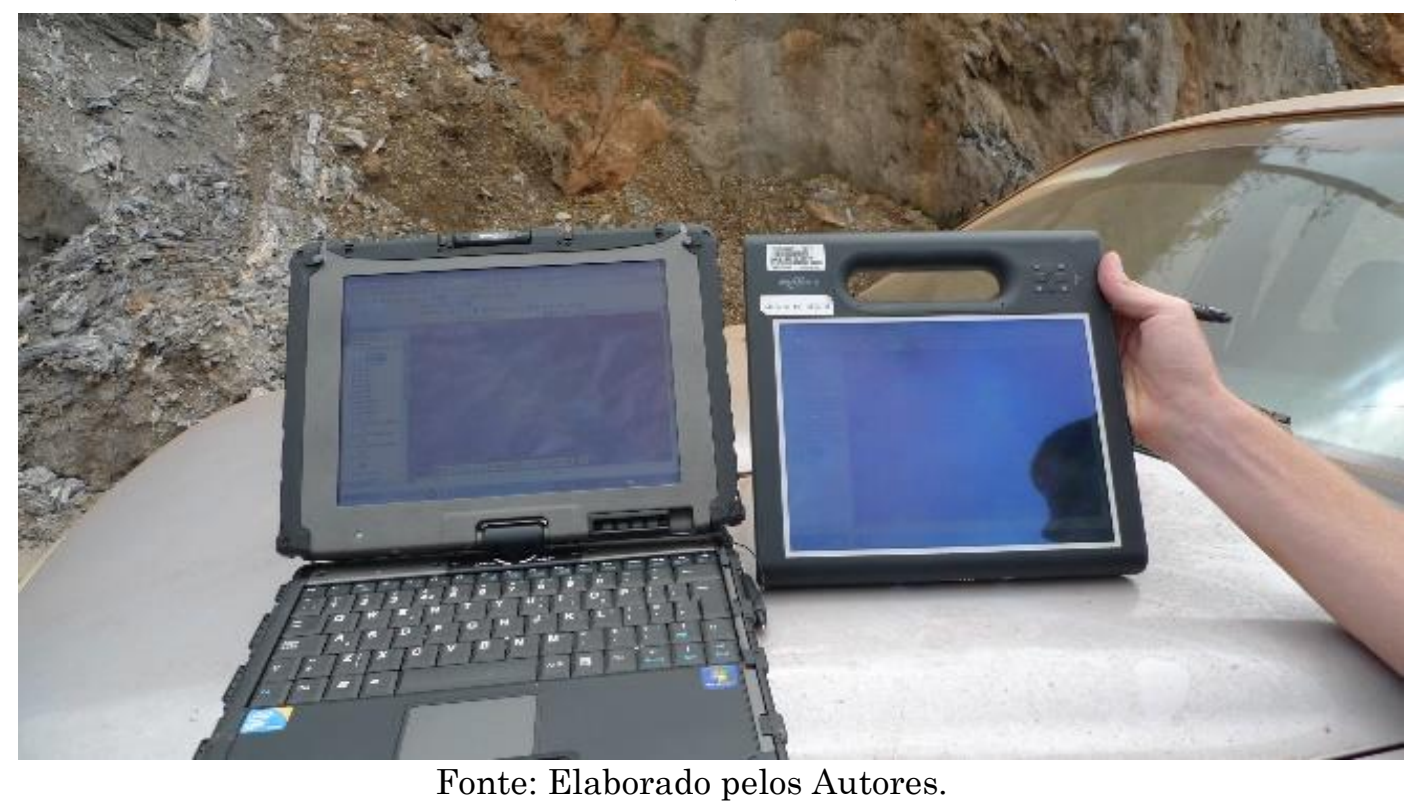


Para o desenvolvimento metodológico desta etapa, Westhead et al. (2013) observam que os progressos na visualização de geoinformações em dispositivos portáteis, do tipo tablets/toughbooks, pode ensejar progressos, por conta das possibilidades criadas para coleta e análise de dados em campo. É ainda perceptível a possibilidade de tratamento e intercâmbio de informações pelos profissionais envolvidos, de forma organizada e objetiva, permitindo a discussão de perspectivas individuais para o trato coletivo do conhecimento das análises em campo. Com a utilização de uma plataforma digital no caso o aplicativo SIGMA Mobile conectado ao ArcGIS, a geovisualização dos dados em campo tem uma nova transformação, já que o profissional pode acessar uma gama de dados, de forma precisa, aprimorando a análise geológica em campo. A produção de dados de forma organizada possibilita a criação de um banco de dados adaptado a diferentes plataformas de armazenamento e tratamento, ampliando a confiança na aquisição e interpretação e posteriormente discussão das informações. Estas premissas foram facilitadas principalmente pela integração SIG/GPS, em um dispositivo móvel, e como reportado por Arruda Junior et al. (2011), traz uma economia temporal e consequentemente financeira. A navegação precisa em cima dos dados (mapas e fotointerpretação), traz acurácia na aquisição de dados e confiabilidade ao executor da atividade, quanto a tomada de decisão em campo, seja os melhores pontos de interesse, assim como as melhores direções a serem seguidas.

As motivações para o estabelecimento de inúmeras tentativas de aprimoramentos nos serviços de campo vieram ainda de outras referências, também reportadas por Whitmeyer (2010), dando conta de que muitos avanços nos estudos de campo para o mapeamento geológico têm sido estabelecidos por programas de pesquisa interessados no desenvolvimento de novas tecnologias (Knoop e Van Der Pluijim, 2006; Whitmeyer et al. 2009; Arruda Junior et al. 2011). Mesmo, que a experimentação conduzida por alguns autores tem trazido bons desenvolvimentos e mostrado o potencial de aplicação destas novas tecnologias nos estudos de campo (Kramer, 2000; 
McCaffrey et al. 2005), estas experimentações necessitam de mais estudos práticos, como descritos por Calazans et al. (2016).

\subsection{Pós-Campo}

Após os trabalhos de campo, prevê-se uma reorganização dos dados, de modo que os mesmos possam ser integrados em uma plataforma $3 \mathrm{D}$, no caso específico aqui tratado o software GeoVisionary, em ambiente de realidade virtual, antes de serem armazenados no banco de dados do projeto. Os dados produzidos construiriam uma plataforma, de modo que possam ser consultados e reutilizados em campanhas de campo posteriores. A associação entre SIG e RV se faz mais intensa nesta fase, aprimorando esta etapa, no que se aproxima da revolução na visualização de dados e informações geográficas, como estabeleceu Westhead (2013), pelo fato do GeoVisionary permitir a geovisualização integrada de terabytes de dados, de mapeamentos geológicos digitais, de ortoimagens de alta resolução, croquis de campo (fieldslips), mapas topográficos antigos, superfície de modelagem topográfica em 3D, modelos geológicos de subsuperfície, seções transversais de investigações de campo e perfis de furos de sondagem geológica, dentre outros dados (Napier, 2011). No caso a aferição de resultados em subsuperficie será relacionada ao modelo geológico $3 \mathrm{D}$ (Leapfrog), em comparação com os resultados de campo, gerando um novo modelo 3D. Ou seja os produtos de campo, não seriam mais apenas, uma representação 2D (mapa geológico) e sim organizados em 3D, através da criação de um modelo implícito no software Leapfrog.

Neste contexto, a integração entre os ambientes de SIG e RV estabelece-se pela interface muito funcional entre o ArcGIS e o GeoVisionary, que instrumentaliza o ambiente de RV. Ressalta-se que os modelos gerados pelo software Leapfrog, podem ser facilmente integrados no GeoVisionary. Este sistema potencializa e mesmo estimula a exploração dos diversos cenários de integração de dados e informações possíveis (Figura 06 e 07). 
Figura 6 - Perspectiva em subsuperfície dos furos de sonda, etapa de pós-campo, em ambiente de realidade virtual, no software Geovisionary.

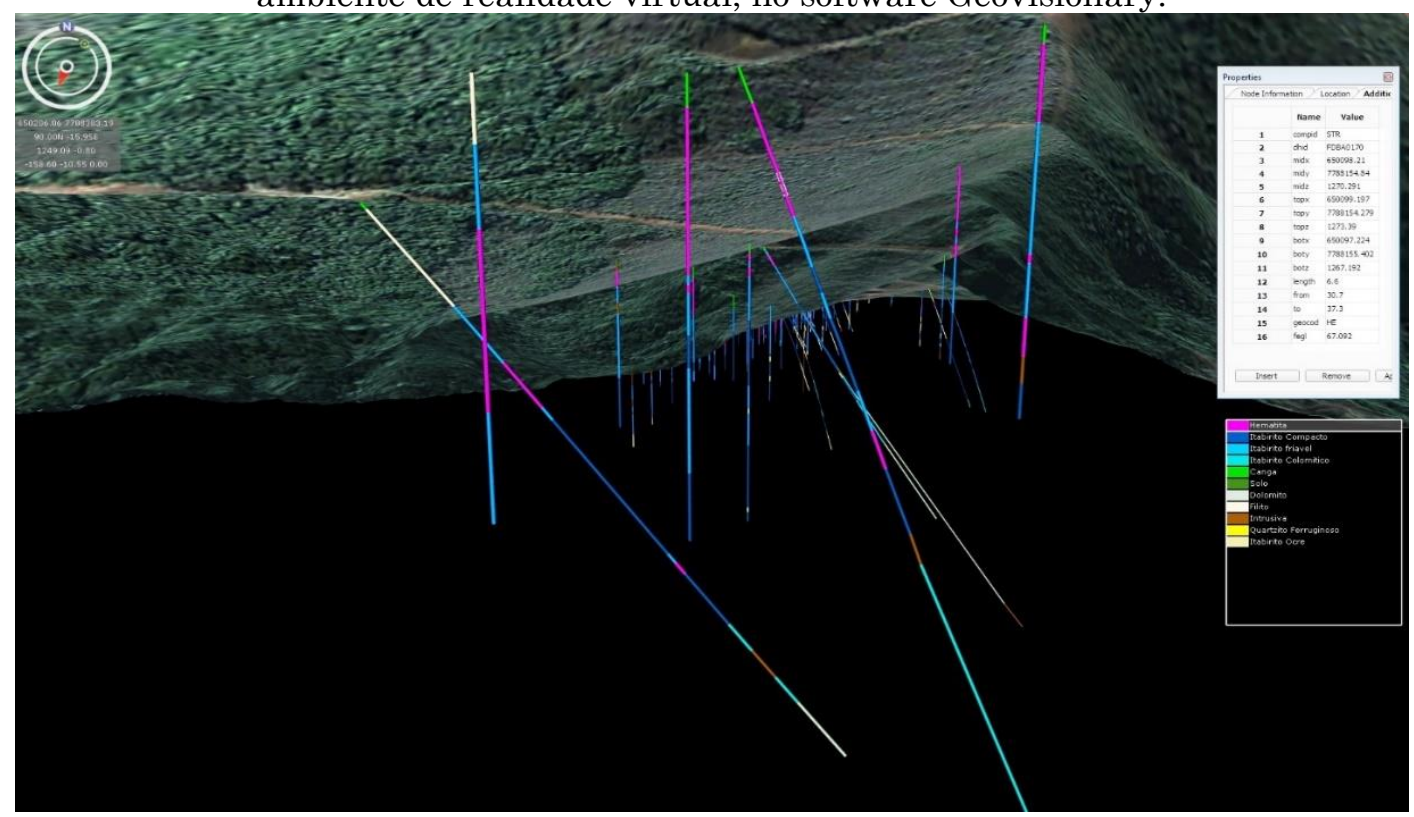

Fonte: Elaborado pelos Autores.

Figura 7 - Cruzamento de modelo geológico implícito com mapa geológico de campo, etapa de pós-campo, em ambiente de realidade virtual, no software Geovisionary.

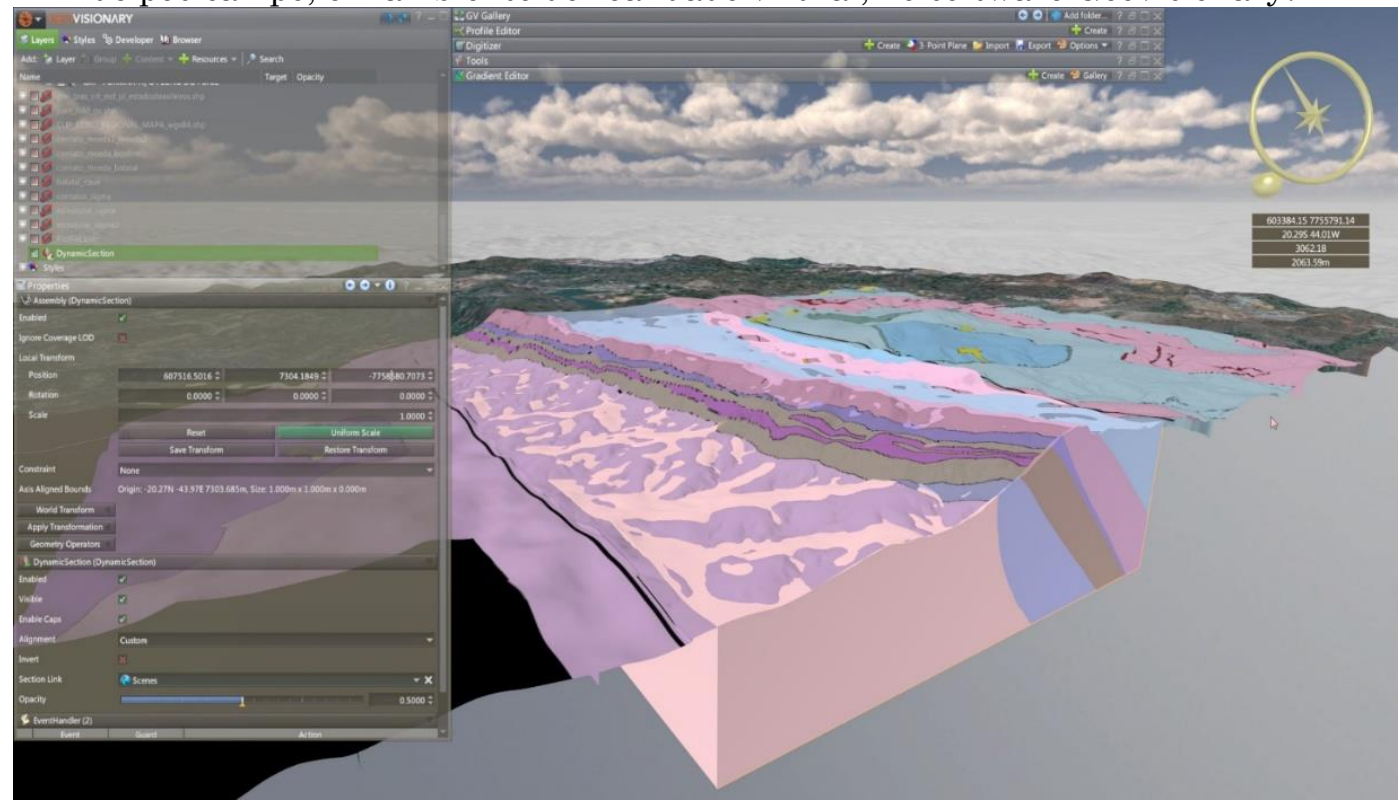

Fonte: Elaborado pelos Autores.

As possibilidades imensas de articulação de cenários em $3 \mathrm{D}$, com a possibilidade de variação criativa da perspectiva de visualização dos dados, motivam a reflexão e a descoberta científicas, permitindo, inclusive que sejam melhores exploradas e postas à prova as modelagens geológicas anteriores aos 
serviços de campo, que agora podem ser aprimoradas ou readequadas, em função dos estudos in loco. Como bem observa WESTHEAD (2013), a perspectiva 3D dos dados de subsuperfície apura a análise e viabiliza percep̧̧ões acerca das evidências geométricas que caracterizam a geomorfologia da Terra, aprimorando a interpretação de elementos estruturais como falhas, dobras e da reconstrução dos ambientes passados de formação da geologia atual (TERRINGTON et al. 2015). A estratégia geral que instruiu a elaboração da metodologia pode ser sinteticamente observada na figura 08, proposta pelo BGS, na integração de diferentes softwares, para as etapas de pré-campo, campo e pós-campo, com inclusão da modelagem implícita, a representação de produtos em 3D, relacionados ao mapeamento geológico.

Figura 08 - A estratégia geral da metodologia, proposta pelo BGS, modificada (em vermelho), com a inclusão da modelagem implicíta através do software Leapfrog, nas etapas de Pré-Campo e Pós-Campo.

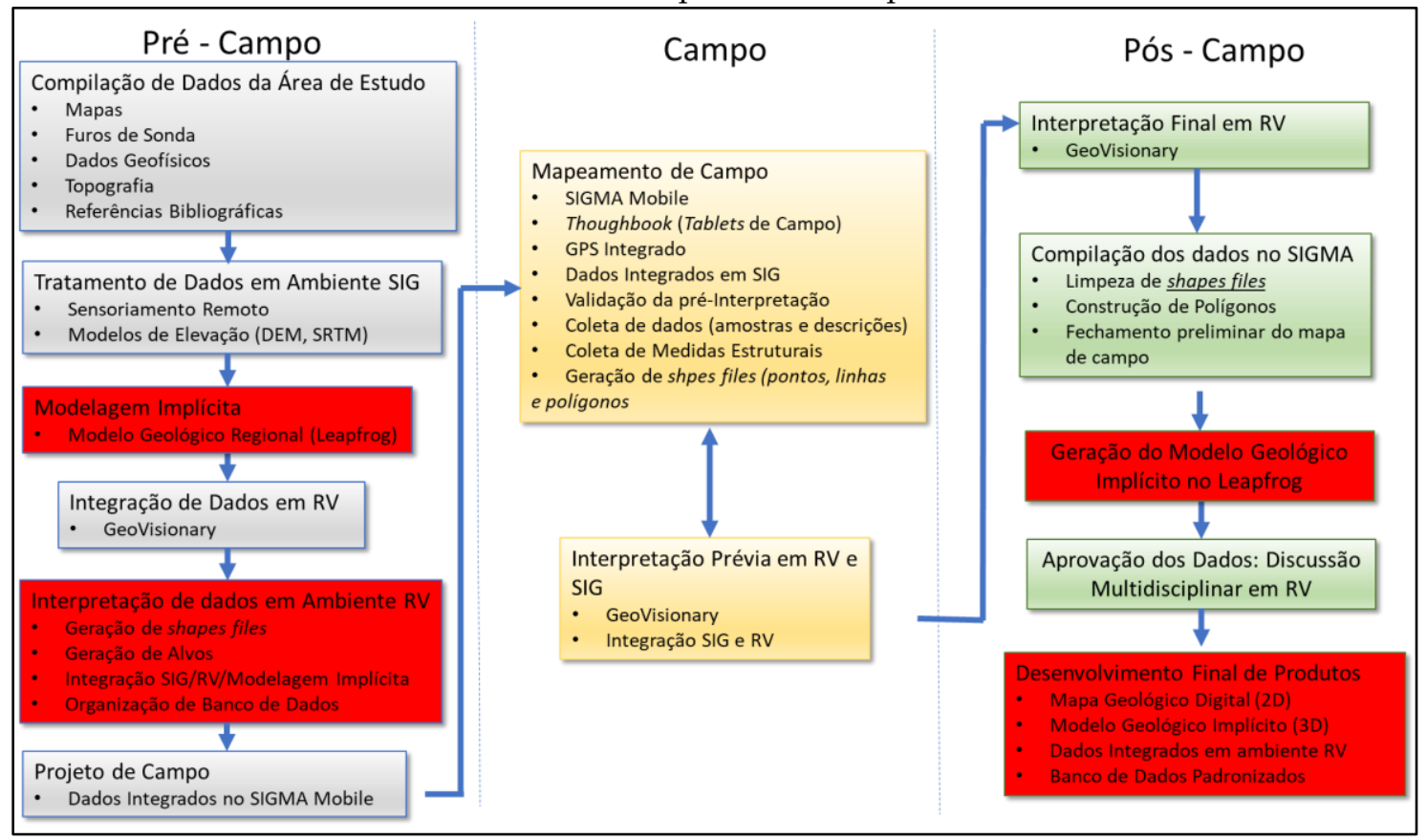

Fonte: Elaborado pelos Autores. 


\section{Discussão}

Os estudos metodológicos aqui reportados, demonstram que no contexto atual do mapeamento geológico, existe uma demanda crescente por melhorar e quantificar os dados de campo de forma precisa e em outras perspectivas de visualização. Cada vez mais, a precisão desta apuração impacta e se torna importante, não apenas para a apreciação do valor dos ativos das empresas e de dados de pesquisa, mas também para uma maior eficiência dos processos extrativos e divulgação de resultados, em face dos custos crescentes e da automação destes processos relacionados a pesquisa geológica.

Nas transformações aportadas pelas novas geotecnologias, em relação à produção de dados, se destacam os sensores remotos de diversos tipos, tais como os de aerogeofísica, os imageadores de altíssima resolução e os sensores ativos de varredura laser, que geram modelos tridimensionais. Não menos importante, entretanto, são os ambientes de integração de dados e produção de análises e informações caracterizadas pelos SIG e RV, que se constituem num dos principais vetores de transformação tecnológica. A integração total de dados nos ambientes SIG ensejou ainda a unificação dos sistemas de georreferenciamento e a crescente preocupação com a qualidade (exatidão) dos dados. Pode-se observar que a quantidade de geodados descritivos disponíveis acerca dos objetos de conhecimento ampliou-se bastante nos últimos tempos, aprimorando muito a base sobre a qual o geólogo pode operar. Um dos aspectos mais interessantes desta percepção das geotecnologias dá conta da possibilidade de representação da dinâmica dos fenômenos. Estas mudanças paradigmáticas muito importantes se associam sinais de outra mudança. Trata-se da a possibilidade de o usuário movimentar o ponto de vista a partir do qual ele observa, num processo similar à situação em que o observador se posiciona em frente a uma maquete tridimensional concreta. Se a isto se associam dados temporais, serão criadas as condições para se 
tratar as questões numa perspectiva quadridimensional, compondo espaço e tempo (Terrington et al. 2015).

A estas considerações conceituais, associam-se aspectos de poder representacional trazidos pelas geotecnologias, que se articulam às questões da prática analítica da Geologia, para destacar quatro questões importantes à constituição das bases de dados, do ponto de vista da Geovisualização, ou seja na relação da visualização e integração de informações (Meneguetti 2013).

A primeira questão trata da representação do território, importante às associações que fazem as análises geológicas entre os fenômenos em estudo e as evidências delas deixadas à mostra no terreno. Há aqui uma ênfase na solução imagética de alta resolução, tanto a produzida através de plataformas satelitais, quanto a produzida por sensores aerotransportados.

A segunda reporta-se ao modelo tridimensional do terreno, que é base para todo o georreferenciamento, em especial à superfície, dos dados de outros levantamentos importantes à caracterização do fenômeno geológico. Esse é o caso das investigações geológico-geotécnicas e geofísicas. Há aqui uma ênfase nas soluções de sensoriamento ativo.

Estas duas questões reportadas, até a pouco tempo se embasavam inicialmente em análises de mapas em meio físico, sobrepostos em mesas de luz para as avaliações correlativas, e na fotointerpretação geológicoestrutural, através de pares estereoscópicos de fotografias, atividades que hoje em dia são feitas de forma mais eficaz, com base no emprego amplo das modernas tecnologias, relacionados aos ambientes SIG e RV. Agregado a isso, os modernos equipamentos móveis (thougbooks e tablets de campo) hoje disponíveis, permitem levar todas essas informações aos estudos de campo, com poderes de avaliação e revisão imediatos, inclusive acessando remotamente a base de dados do escritório (Whitmeyer et al. 2010). No passado, essa atividade somente era possível após o retorno ao escritório dos mapas e cadernetas em papel contendo as anotações verificadas em campo. Acresce-se a isso o fato importante de que os SIG associados a estes 
dispositivos possibilitam uma integração total de dados diversos, que tornam as análises de mais precisas e dinâmicas, conforme observado por Athey et al. (2008).

Para além da questão da importância da geovisualização 3D para a Geologia, deve-se destacar que a camada superficial da Terra é a georreferência para a ancoragem de todos os tipos de levantamentos subterrâneos, desde investigações geológico-geotécnicas até diversas formas de sensoriamento remoto geofísico. Neste contexto, um desenvolvimento geotecnológico que permita a geração de modelos digitais de terreno mais precisos, mais representativos da real conformação da superfície, melhora a qualidade da representação dos levantamentos subterrâneos. $\mathrm{Na}$ evidenciação disso se pode recorrer a Braga et al. (2010), quando ele estabelece que, em aerolevantamentos geofísicos, os cálculos para remover o efeito do terreno demandam uma modelagem precisa da superfície topográfica local. O autor estabelece ainda que a comparação entre processamentos de dados geofísicos feitos com base em modelos digitais detalhados, obtidos através de perfilamento laser, e processamentos feitos com base em modelos mais generalizados, como o SRTM, evidenciaram a importância de um MDT preciso e representativo, no processo de correção dos dados de aerogradiometria gravimétrica 3D-FTG (Full Tensor Gradiometry).

Esta associação da modelagem de terreno com base no laser e a do processamento de dados de aerogeofísica enfatiza outro aspecto importante da evolução das geotecnologias, isto é a interação entre dados multidisciplinares nos meios geoinformacionais. No caso da constituição da base de dados geográficos para apoio às atividades geológicas identifica-se uma crescente opção pela representação tridimensional. A adoção desta solução foi orientada pela convicção de que a precisão dos dados de modelagem tridimensional do terreno, como identificada por Braga et al. (2010), traria ganhos expressivos para os levantamentos geofísicos e geológicos, que utilizam este modelo como referência. Esta solução viabiliza que, em sistemas computacionais especialistas, se faça de forma muito mais rica a geração de 
blocos-diagrama virtuais, modelos tridimensionais e dinâmicos, muito mais substanciais e poderosos do que seus antecessores históricos.

A terceira questão está conectada aos softwares relacionados ao mapeamento geológico (SIG, RV), convém uma referência a Longley et al. (2001), que já haviam destacado que os ambientes digitais de representação da geoinformação melhoraram a interpretação de informações que, nas bases convencionais dos mapas, eram impraticáveis. Operar atividades de interpretação como extrair medidas, superpor, combinar e comparar mapas e fazer variar a escala, dentre outras ações, eram tarefas cuja execução era muito trabalhosa no mapa convencional, exigindo até certa habilidade ou experiência prévia para seu desempenho. Nesta mesma argumentação, Bonham-Carter (1994) chama a atenção para o fato de que os SIG têm o potencial de liberar seus usuários de atividades técnicas, lentas e trabalhosas de manipulação de dados, deixando mais tempo para as criativas análises e interpretações das informações.

Os sistemas SIG e RV, aplicados a Geologia, neste caso, destacam-se pelo grande poder integrador e analítico que disponibilizaram ao trabalho cotidiano da análise, planejamento, modelagem, etc. No caso específico da modelagem geológica para melhor entendimento da subsuperfície, estimativa de corpos de minério, a integração e a análise de dados de diversas origens em ambientes geoinformacionais, com visualização mais sofisticada. Diversas são as indicações de que este processo de potencialização à análise e à exploração mineral encontra um reconhecimento científico e tecnológico. Como observado em Westhead et al. (2012), Whitmeyer et al. (2010) e Terrington et al. (2015), existe uma crescente demanda pela qualidade das representações, orientada pela necessidade de melhor detalhar e embasar as análises, para otimizar e tornar mais preciso o mapeamento geológico e a pesquisa mineral.

A possibilidade de análise das informações em ambiente RV enriquecese ainda mais, porque a capacidade de articulação e composição dos dados 
apresentados nos SIG, inclusive pela inter-relação entre diferentes tipos de imagens e dados, é muito maior do que aquela em plataforma 2D.

A quarta questão está relacionada com a apresentação dos dados da atividade de mapeamento geológico, geralmente condicionada a mapas e perfis (seções geológicas), em representação 2D. Com o crescente desenvolvimento de softwares de modelagem e ambiente RV, para apresentação e integração de dados, observa-se a necessidade de adequação dos produtos gerados em campo (mapas e perfis) à nova perspectiva das geotecnologias. A modelagem geológica está amplamente divulgada na indústria mineral, mas com intuito de aferição de teores e volumes dos corpos minerais, e não a representação do ambiente geológico. A metodologia mais comum para a modelagem é a explicita, que ocorre por digitação de contatos e construção de corpos de forma manual (Cowan et al. 2003), ou seja, na triangulação de objetos para representação da geometria do corpo, também conhecido como o "método das seções". Este método demanda tempo, e conforme discussões propostas por Conwant et al. (2003 e 2004), apresenta imprecisões, e dependente de outras informações de subsuperfície tais como testemunhos de sondagem. Os mesmos autores apresentam a modelagem implícita como um meio de diminuir a imprecisão e tempo, na modelagem geológica. Tratando-se de um mapa geológico, e na preposição proposta aqui neste trabalho, esta metodologia de modelagem implícita traria benefícios para a de geovisualização de dados geológicos de campo. Ou seja, os modelos geológicos 3D podem ser criados a partir de mapas geológicos, de forma rápida e precisa, contanto que os dados de campo tenham a mesma qualidade e sejam organizados em plataforma digital acessível ao software de modelagem (Cowan et al. 2004). A transformação metodológica nesta questão está ligada ao fato de uma nova perspectiva na representação dos dados de campo, passando da forma $2 \mathrm{D}$ para uma forma $3 \mathrm{D}$, mais rica em detalhes e ampliando a geovisualização dos dados. Este aprimoramento estaria relacionado nas etapas de pré-campo, com a construção de um modelo geológico implícito a partir do mapa geológico regional, contribuindo para uma visão $3 \mathrm{D}$ pelo 
geólogo de campo em sua preparação para o mapeamento. Na etapa de póscampo, onde são criados os produtos do mapeamento geológico, resultaria também na forma de um bloco diagrama tridimensional (modelo geológico).

A metodologia do BGS, incorpora muitas dessas discussões, entretanto sem apresentar a modelagem implícita como um fator no mapeamento geológico e pesquisas associadas (Figura 08) - vide subcapitulo 3.3.

$\mathrm{O}$ crescimento constante da base de dados juntamente com o avanço das geotecnologias, impõe como necessárias especificações metodológicas para organização e normatização de dados para o ambiente SIG/RV. Ou seja, a organização do banco de dados e das geoinformações devem possuir regras para controle de inserção, modificação e criação, Calazans (2015). Como observado por essa autora, essa normatização se mostra cada vez mais necessária, na medida em que a crescente adição e demanda de dados se torna mais complexa, para estruturação, tratamento e produção de geoinformações. A integração de dados em ambiente RV depende desta organização; um exemplo seria a unificação de referenciais geodésicos, sistema de coordenadas geográficas. Estes diferentes ambientes de geovizualização podem causar distorção e incongruências nos dados, tornando assim uma normatização de informações essencial. Calazans (2015), discute que os ambientes de geovizualiação estão em franco desenvolvimento, e deixa evidente a importância estratégica da associação SIG/RV. A autora propõe comparações da metodologia usual com a nova metodologia em desenvolvimento, sinalizando que os processos relacionados ao mapeamento geológico, poderão ter mudanças significativas. Esses pontos críticos foram sintetizados em uma tabela (Tabela 01), com os possíveis aprimoramentos da utilização de novas técnicas. A mesma autora, em outro trabalho (Calazans et al. 2016), sinaliza que a metodologia necessita de adequações, e continua em progresso, com o surgimento de novas geotecnologias. Este ponto é abordado aqui e representado na Tabela 01, com a introdução da modelagem implícita nas etapas de pré-campo e pós-campo. 
A análise comparativa das metodologias, sinaliza que está em curso uma mudança de paradigma em relação ao trabalho de análise geológica, de ambientes 2D para o 3D. Os ambientes futuros de trabalho poderão ser bem diferentes dos de hoje, permitindo ao usuário ter uma maior perspectiva e precisão nas análises geológicas nas etapas de mapeamento, permitindo a otimização e eficácia dos resultados, viabilizando a redução de tempo com e o planejamento mais preciso das atividades de campo. 
TABELA 1 - Comparação dos métodos; tradicional, usualmente praticado, e a nova metodologia baseada nas tendências relacionadas a geotecnologia, com a adoção da modelagem implícita nas etapas de Pré-Campo e Pós-Campo (destacada em vermelho). Na coluna "Aprimoramentos", está descrita uma sintetização dos resultados sobre a adoção de novas técnicas de geovizualição e ferramentas associadas as novas geotecnologias.

\begin{tabular}{|c|c|c|c|}
\hline Etapa & $\begin{array}{l}\text { Metodologia } \\
\text { Tradicional }\end{array}$ & Metodologia Proposta & Aprimoramentos \\
\hline \multicolumn{4}{|l|}{ PRÈ-CAMPO } \\
\hline Identificação de Área de Pesquisa & $\begin{array}{l}\text { Salas de reuniões e mapas (2D) eram } \\
\text { utilizados para definição das áreas } \\
\text { prioritárias de pesquisa }\end{array}$ & $\begin{array}{l}\text { Salas ou computadores com visualização de } \\
\text { dados integrados em ambiente RV (3D), }\end{array}$ & $\begin{array}{l}\text { Fácil visualização das áreas focos de } \\
\text { pesquisa e participação de equipe } \\
\text { multidisciplinar }\end{array}$ \\
\hline Preparação dos Dados & $\begin{array}{l}\text { Dados preparados para ambiente 2D e } \\
\text { impressos }\end{array}$ & $\begin{array}{l}\text { Dados preparados e normatizados para } \\
\text { utilização em ambiente } 3 \mathrm{D} \text { e } 2 \mathrm{D}\end{array}$ & $\begin{array}{l}\text { Utilização de um banco de dados } \\
\text { normatizados para utilização em múltiplos } \\
\text { ambientes 2D(ARCGIS) e 3D (Geovisionary) } \\
\text { e exportação dinâmica para o software de } \\
\text { campo (SIGMA Mobile) }\end{array}$ \\
\hline Modelamento Geológico Prévio & Não existe & $\begin{array}{l}\text { Preparação de um modelo geológico regional } \\
\text { implicíto, a partir de dados da bibliografia e } \\
\text { acervo interno }\end{array}$ & $\begin{array}{l}\text { Aumento da percepcção do espaço e } \\
\text { ambiente geológico, com a perspectiva 3D }\end{array}$ \\
\hline Integração de Dados & Integração parcial em ambiente ARCGIS & Integrados em ambiente RV (3D) & $\begin{array}{l}\text { Visualização de uma enorme gama de dados } \\
\text { em altíssima resolução }\end{array}$ \\
\hline Interpretação de Dados & Ambiente 2D, sem fotointerpretação & $\begin{array}{l}\text { Interpretação em ambiente RV(3D) com dados } \\
\text { multidisciplinares integrados. Fotointerpretação } \\
\text { de imagens e dados multidisciplinares, geração } \\
\text { de dados e exportação direta para o SIGMA } \\
\text { Mobile. }\end{array}$ & $\begin{array}{l}\text { Participação de equipe multidisciplinar, } \\
\text { fotointerpretação de altíssima qualidade } \\
\text { gráfica. Dados interpretados gerados de } \\
\text { forma eficiente e de fácil manipulação, com } \\
\text { exportação dinâmica para o software de } \\
\text { campo. }\end{array}$ \\
\hline \multicolumn{4}{|l|}{ CAMPO } \\
\hline Material de Campo & $\begin{array}{l}\text { Caderneta, Bussola, Martelo, câmera } \\
\text { fotográfica, GPS, mapas impressos em } \\
\text { alguns casos ocorre a utilização do } \\
\text { ARCPAD e Laptop. }\end{array}$ & Martelo, Bússola e tablet. & $\begin{array}{l}\text { Menor gama de equipamentos, facilitando a } \\
\text { condução dos trabalhos de campo de forma } \\
\text { dinâmica e eficiente. Possibilidade de não } \\
\text { utilização de mapas impressos. }\end{array}$ \\
\hline Visualização dos Dados & $\begin{array}{l}\text { Mapas Topográficos, Geológicos, } \\
\text { Imagens Aeras ou Satélites, impressos } \\
\text { em papel de tamanho variável }\end{array}$ & $\begin{array}{l}\text { No tablet, mapas multidisciplinares e imagens } \\
\text { integrados }\end{array}$ & $\begin{array}{l}\text { Dados multidisciplinares integrados prontos } \\
\text { para consulta em campo, facilitando a } \\
\text { interpretação e discussão na condução dos } \\
\text { trabalhos. }\end{array}$ \\
\hline Aquisição dos Dados & $\begin{array}{l}\text { Anotação em caderneta ou arcpad, } \\
\text { marcação de pontos em GPS, utilização } \\
\text { de câmera fotográfica para registro de } \\
\text { imagem do ponto. }\end{array}$ & $\begin{array}{l}\text { No tablet, o mesmo possui planilha de dados } \\
\text { para registro de pontos topológicos, } \\
\text { geológicos, estruturais, câmera integrada com } \\
\text { possibilidade de interpretação gráfica da } \\
\text { imagem, GPS integrado com visualização em } \\
\text { tempo real nas imagens e mapas }\end{array}$ & $\begin{array}{l}\text { Rapidez e eficiência na aquisição de dados, } \\
\text { diminuição do erro devido a integração } \\
\text { GPS/Tablet/Mapa. O mapa é gerado em } \\
\text { campo, juntamente com outras interpretações. }\end{array}$ \\
\hline $\begin{array}{l}\text { Trabalho em escritório (Durante a } \\
\text { Campanha de Campo) }\end{array}$ & $\begin{array}{l}\text { Em laptop, download dos dados do GPS, } \\
\text { fotos da câmera, digitação das anotações } \\
\text { da caderneta de campo. Integração dos } \\
\text { dados baixados e anotados, e } \\
\text { interpretação dos registros de campo no } \\
\text { computador. }\end{array}$ & $\begin{array}{l}\text { Os dados de campo são revisados no próprio } \\
\text { tablet, as interpretações de campo, ocorrem } \\
\text { durante esta atividade. Os pontos podem ser } \\
\text { exportados em planilhas e diretamente } \\
\text { utilizados para criação de stereogramas. } \\
\text { Relatórios de campo podem ser gerados com } \\
\text { apenas um click (automático), resultando em } \\
\text { um documento com planilhas, fotos, descrição } \\
\text { e etc. }\end{array}$ & $\begin{array}{l}\text { Revisão e correção dos dados de campo no } \\
\text { mesmo software e hardware de trabalho. } \\
\text { Aquisição de dados digitais em ambiente } \\
\text { integrados (GPS/GIS/Câmera) evita erro de } \\
\text { digitação, e garante ganho de tempo e } \\
\text { eficiência/qualidade na geração de } \\
\text { resultados. }\end{array}$ \\
\hline \multicolumn{4}{|l|}{ PÓS - CAMPO } \\
\hline Visualização de Resultados & $\begin{array}{l}\text { Os resultados do campo são impressos } \\
\text { em mapas (2D), relatórios e planilhas. }\end{array}$ & $\begin{array}{l}\text { Os resultados de campo são visualizados em } \\
\text { ambiente 3D, com integração dos mesmos }\end{array}$ & $\begin{array}{l}\text { Participação de equipe multidisciplinar, fácil } \\
\text { visualização e manipulação dos dados } \\
\text { totalmente integrados }\end{array}$ \\
\hline Modelamento Geológico Final & Não existe & $\begin{array}{l}\text { Execução de um modelo geológico da área } \\
\text { mapeada, a partir de dados de campo }\end{array}$ & $\begin{array}{l}\text { Apresentação dos resultados de campo em } \\
\text { 3D, saindo do convencional, apenas mapas e } \\
\text { perfis em perspectiva 2D }\end{array}$ \\
\hline Discussão de Resultados & $\begin{array}{l}\text { Discussão em salas de reuniões e } \\
\text { possíveis alterações a mão, para serem } \\
\text { revisadas posteriormente. }\end{array}$ & $\begin{array}{l}\text { Em ambiente 3D, com dados integrados de } \\
\text { fácil visualização de uma equipe } \\
\text { multidisciplinar. }\end{array}$ & $\begin{array}{l}\text { Discussão mais sólidas e ricas de informação } \\
\text { devido a integração dos dados de campo e } \\
\text { utilização do ambiente RV. }\end{array}$ \\
\hline
\end{tabular}

Fonte: Modificado de Calazans (2015). 
Da perspectiva da interatividade, parece sensato considerar que a representação pode melhorar a intermediação deste com o fenômeno estudado, e que assim, a transformação das representações 2D (estáticas) e estáticas em 3D (dinâmicas) levaria à percepção do usuário sobre a realidade prevista em campo. Não se trata de uma visão de tirar o geólogo do campo; não é este o objetivo. Trata-se, sim, de prolongar pela representação em realidade virtual a sua experiência de campo.

Em termos do mapeamento geológico, seria, natural que os dados fossem representados em 3D, o que não é, entretanto, uma prática comum. Neste sentido, o foco dos desenvolvimentos em curso na geovisualização de dados geológicos está orientado em disseminar o uso dos ambientes tridimensionais. É importante considerar, também, que tanto para a mineração como para questões ambientais o tempo é um condicionante essencial, e pode facilmente ser necessário implementar o 4D, ou seja, incorporar a quarta dimensão, o tempo, às discussões da representação de dados geográficos no contexto geológico, como observado por Calazans (2015). O tempo é uma variável importante no planejamento do mapeamento, e dados cada vez mais complexos e de qualidade são necessários para a análise temporal. A demanda crescente por imagens em alta e altíssima resolução, coletadas em diversas épocas, formando uma série temporal de imagens, parece ser um sinal claro desta valorização da relação espaço - tempo no contexto da análise e do planejamento (Büchi et al. 2006).

Ainda com base no uso futuro previsto dos ambientes de RV, vale trazer à discussão questões como a importância destes ambientes na avaliação de impactos e desdobramentos das intervenções ambientais projetadas, que devem se tornar cada vez mais realistas, permitindo a idealização de empreendimentos mais sustentáveis; e ainda, melhorias das análises de riscos, planos de ação de segurança e estudos geológicos e ambientais, dentre outros, que sinalizam tornar-se mais efetivos, inclusive pelo maior compartilhamento interdisciplinar de conhecimento. 
Há, portanto, diversas transformações em curso na relação entre a geologia e as representações geoinformacionais. A própria geologia, nas expectativas em relação às análises e na evolução natural de seu conhecimento específico vive um novo tempo. Parece pertinente observar, neste contexto, que as representações gráficas que são importantes como geoinformações à geologia "revelam mais do que feições geológicas, elas são produtos de uma circunstância histórica, portanto são imagens tanto do estado da arte da geologia como da própria cartografia geológica" (Machado et al. 2010). Neste sentido observa-se uma construção conceitual da Geologia. O autor Westhead et al. (2013) sintetiza bem as mudanças em curso na análise geológica, ao observar que, no futuro, provavelmente não muito distante, os analistas serão capazes de fatiar um modelo geológico, não apenas para gerar um mapa da geologia de superfície, mas sim para caracterizar modelos em qualquer profundidade especificada, até quilômetros abaixo da superfície, conforme a demanda de seu interesse.

Com relação às questões mais específicas aqui apresentadas, vale destacar para desenvolvimentos futuros, os seguintes aspectos a considerar. A decisão pela escolha dos softwares envolvidos é estratégica, por conta do importante papel de sistema operacional que eles cumprem em todas as fases do trabalho, do pré-campo ao pós-campo. SIGMA Mobile, ArcGIS, GeoVisionary e Leapfrog foram os que mais se destacaram na proposta de desenvolvimento;

a) O investimento na interpretação de dados antes, durante e após os trabalhos de campo não apenas amplia a qualidade das análises, como também leva a uma tendência pela melhor qualidade das atividades de campo, maximizando o tempo destas inspeções in loco e evitando as revisitas para esclarecimento de dúvidas;

b) As possibilidades crescentes de aquisição e articulação de grandes quantidades de dados e de produção de informações pressupõe uma padronização destes dados e informações (metadados). A natureza 
dinâmica da base de dados impõe como necessária uma gestão que a mantenha estruturada e eficiente;

c) As geotecnologias estão em desenvolvimento acelerado, o que gera a necessidade de estar sempre atento as inovações relacionadas a geociências;

d) A complexidade das transformações é bastante grande, e neste sentido, as parcerias com outras instituições, acadêmicas e da indústria, são muito importantes à manutenção de um ritmo significativo de evolução.

e) Não se deve perder de vista que as mudanças metodológicas na exploração mineral e mapeamento geológico implicam em certa mudança cultural nos ambientes de trabalho tradicionais da exploração mineral. Programas de treinamento, divulgação e conscientização acerca das novas tecnologias são muito importantes à superação das resistências naturais às mudanças operacionais.

\section{Conclusão}

As discussões e análises aqui reportadas, demonstram que as geotecnologias, atreladas a geovizualiação, conduzem a melhorias significativas nos processos associados a exploração mineral, em especial pela utilização de ambiente SIG e RV. As melhorias metodológicas destacadas, são relevantes e perfeitamente aplicáveis. Uma das etapas mais importantes do trabalho de pesquisa geológica, que são as investigações de campo, é otimizada pelas mudanças previstas na interpretação, aquisição e representação de dados.

A aplicação destes aperfeiçoamentos metodológicos na pesquisa geológica vem sendo testada em trabalhos pontuais e periódicos, principalmente no exterior, sendo de extrema necessidade aplicação destes novos métodos no país. 
As atividades de mapeamento geológico e exploração mineral têm se tornado complexas nestes ambientes geotecnológicos. Isso parece reafirmar a mudança de paradigma de $2 \mathrm{D}$ para $3 \mathrm{D}$ e $4 \mathrm{D}$ nas geoinformações como um todo e nas análises geológicas em geral, reforçando a importância de preparar as equipes de trabalho para mudanças futuras de seus ambientes de análise, estudos, projetos e tomadas de decisão, principalmente pela associação entre o SIG e RV. Além disso, as atividades relacionadas a exploração mineral estão lidando cada vez mais com restrições ambientais, fato que gera demanda crescente por representações mais ricas e sofisticadas do seu território de intervenção. Investimentos em ambientes sofisticados de geovisualização deverão criar condições para melhorar as análises, em termos de precisão, e tornar os planos de ação e a implantação de projetos cada vez mais bem ajustados à realidade no terreno

Esta mudança de paradigma (2D a 3D) não é, no entanto, uma coisa simples. Há uma série de desafios a considerar, nos aspectos tecnológico, cultural, operacional, financeiro e outros. A maneira para ir à busca das soluções possíveis e dos caminhos de especificação de processos parece ser o da experimentação tão extensa quanto possível, a fim de identificar o contexto mais adequado de trabalho para estas novas realidades. Entretanto, como observado por Whitmeyer et al. (2009), existem desvantagens para o mapeamento digital e os métodos de apresentação de mapas geológicos aqui discutidos. Com o desenvolvimento rápido das getecnologias, é necessário tempo para que o usuário se sinta confortável com os novos hardwares e softwares das etapas da pesquisa mineral, sendo necessário backups contínuos dos dados coletados e por sinal até cópias impressas dos resultados. A falta de padronização e normatização de dados impede a transferência rápida entre os ambientes de geovizualização. A solução seria criar processos integradores, ou até scripts mais atualizados, para comprir com essa demanda.

Os dispositivos móveis de campo, além do alto custo do equipamento, não apresentam ainda duração de bateria suficiente para um dia completo de 
trabalho, sendo necessário ter sempre uma reserva para os trabalhos de campo. Os softwares relacionados a RV, ainda são dispendiosos em termos financeiros, assim como os hardwares e equipamentos atrelados (monitores $3 \mathrm{D}$, projetores 3D, mouses 3D). Entretanto os métodos aqui apresentados não são mais um luxo, e sim constituem uma ferramenta necessária para o continuo desevolvimento da geovizualiação aplicada a geologia.

Este trabalho teve a intenção de contribuir para uma melhor compreensão da relação entre as análises geológicas e as geotecnologias que as apoiam. Sua finalidade esteve orientada para a evidenciação das melhorias que as geotecnologias têm trazido à produção do conhecimento em Geologia, de forma a não apenas contribuir para um aprimoramento da especificação dos dados geográficos a produzir para essas atividades, mas também para explorar e discutir as novas contribuições possíveis das diferentes geotecnologias no contexto dos estudos geológicos.

As geotecnologias estão em franco desenvolvimento, sinalizam claramente que o processo de desenvolvimento da exploração mineral e mapeamento geológico está longe de seu esgotamento. Em pleno curso, a evolução das tecnologias sinaliza, contrariamente, que as representações geoinformacionais e as análises quadridimensionais, conciliando espaço tridimensional e tempo, estão ainda num estágio inicial de um processo de franca evolução.

\section{Agradecimentos}

Os autores agradecem a equipe do BGS pelas discussões técnicas relativas ao tema proposto e parceria acadêmica e a FAPEMIG por ceder recursos na forma de bolsa de pesquisa para este trabalho de mestrado. 


\section{Referências}

ARRUDA JUNIOR, E. R.; SEOANE, J. C. S.; MENEZES, P. M. L., L. Geotecnologias Portáteis e Produtos Gratuitos ou de Baixo Custo no Auxílio ao Mapeamento. Revista Brasileira de Cartografia, vol. 62, 2010. pp. 269-276.

ATHEY, J. E.; FREEMAN, L. K.; WOODS, K., A. The Transition from Tradiotional to Digital Mapping: Maintaining Data Quality While Increasing Geologic Mapping Efficiency in Alaska. Alaska GeoSurvey News, vol. 11, n. 2, 2008. BONHAM-CARTER, G. F. Geographic Information Systems for Geoscientists:

Modeling with GIS. Pergamon/Elsevier Science Publications, 1994. 416p.

BRAGA, M. A.; CARLOS, D., U.; SOUSA, R., R.; GALBIATTI, H.; ALMEIDA, T. Correção de terreno para dados de aerogradiometria gravimétrica 3D-FTG no Quadrilátero Ferrífero, Minas Gerais, Brasil. Revista Brasileira de Geofisíca, vol. 28, n. 4, 2010. pp. 703-722.

BÜCHI, A.; KARFUNKEL, J.; HOFMANN, M.; PIMENTA, F.; PAGUNG, R.; HOPPE, A.; FREITAS, C. R. Análise Multi-Temporal dos Georecursos ao norte de Belo Horizonte (MG): Estudo de Caso do Aluvião do Ribeirão da Mata. Anais do: XLIII Congresso Brasileiro de Geologia, Aracaju -SE, 2006. 379p.

CALAZANS, P. M. P. Geovisualização em Ambientes de Realidade Virtual: Mudança de paradigma na Exploração Mineral de Ferrosos. Tese de Doutoramento. Universidade Federal do Rio de Janeiro Instituto de Geociências, Programa de Pós-graduação em Geologia, 2015. 371p.

CALAZANS, P. M. P.; CASTIGLIONE, L. H.; BÜCHI, A.; SEOANE, J. C. S. NAPIER B.; FORD, J. Geovizualização em Ambientes de Realidade Virtual e sua Aplicação na Exploração Mineral. Revista Brasileira de Cartografia, vol. 68, n.1, 2016. pp. 43-61.

CASTIGLIONE, L. H. G.; CALAZANS, P. M. P. A constituição de uma base de dados geográficos para apoio a estudos geológicos: aspectos epistemológicos e práticos. Anais do $15^{\circ} \mathrm{SBSR}$ - Simpósio Brasileiro de Sensoriamento Remoto, Curitiba - PR, 2011.

COE, A. L.; ARGLES, T. W.; ROTHERY, D. A. e SPICER, R. A. Geological Field Techniques. Press XII Wiley-Blackwell/Open University, 2010. 323p. 
COWAN E. J.; BEASTON, R.K.; ROSS, H.J.; FRIGTH, W.R.; MCLENNAN, T.J.; EVANS, T.R.; CARR, J.C.; LANE, R.G.; BRIGHT, D.V.; GILLMAN, A.J.; OSCHURT, P.A. e TITLEY, M. Practical Implicit Geological Modelling.

Proceedings of 5th International Mining Geology Conference, AusIMM Publication Series, 2003. pp. 89-99.

COWAN, E. J.; LANE, R. G.; ROSS, H. J. Leapfrog's implicit drawing tool: a new way of drawing geological objects of any shape rapidly in 3D, in Mining Geology. 2004 Workshop (eds: M.J. Berry and M.L. Quigley), Australian Institute of Geoscientists Bulletin, vol. 41, 2004. pp. 23-25.

CUVIER, G.; BRONGNIART, A. Essai sur la Géographie Minéralogique des Environs de Paris, avec une Carte Géognostique, et des Coupes de Terrain. Paris, Baudouin, 1808. 278 p.

GOETZ, A. F.; ROCK, B. N.; ROWAN, L.C. Remote Sensing for exploration: an overview. Economic Geology, v.78, 1983. pp. 570-73.

GUIMARAES FILHO, H. A. Metodologias para intercâmbio de dados entre programas de CADD, SGBD, PDI e SGI em projetos de exploração mineral. Campinas: Instituto de Geociências. Dissertação de Mestrado, Universidade Estadual de Campinas, 1994. 118p.

JÉBRAK, M. Innovation in mineral exploration: successes and challenges. SEG. Newsletter, vol. 86, 2011. pp. 12-13.

JORDAN, C. SIGMA mobile: the BGS digital field mapping system in action: in the United Arab Emirates. Proceedings of $9^{\circ}$ Digital Mapping Techniques Congress, West Virginia, USA, 2009. British Geological Survey. (Unpublished)(http://nora.nerc.ac.uk/7482/)

JORDAN, C.; BATESON, L.; BOW, J.; NEWELL, A.; NAPIER, B.; SABINE, R, J. GeoVisionaryTM software for 3D visualisation and petroleum exploration in southern Tajikistan. Proceedings of RSPSoc: New Dimensions in Earth Observation, Leicester, UK, 2009. pp. 8-11. (Unpublished) (http://nora.nerc.ac.uk/8854/).

JORDAN, C, e NAPIER, B. Developing digital fieldwork technologies at the British Geological Survey. In: Bowman, M.; JORDAN, C.J. The value of outcrop studies in reducing subsurface uncertainty and risk in hydrocarbon exploration 
and production. Geological Society Special Publication, vol. 436, 2016. pp. 219-229.

KNOOP, P.A. e VAN DER PLUIJIM, B. GeoPad: Tablet PC-enabled Field Science Education. In: "The Impact of Pen-based Technology of Education: Vignettes, Evaluations, and Future Directions". D. Berque, J. Prey, and R. Reed. Purdue University Press,2006. 133p.

KRAMER, J. H. Digital Mapping Systems for Field Data, in Soller, D.R., editor, Digital Mapping Techniques. Workshop proceedings: U.S. Geological Survey Open-file Report, Lexington, Kentucky, 2000. 325p.

LONGLEY, P. A.; GOODCHILD, M. F.; MAGUIRE, D. J. e RHIND, D. W. Geographic Information Systems and Science. Chichester: Wiley. .2001. $320 \mathrm{p}$.

MACHADO, M. M. M.; RENGER F. E.; RUCHYS, U, A. Estruturas Dobradas do Quadrilátero Ferrífero em Perfis Geológicos do Século. Geonomos, v. 18, n. 2, 201. pp. 73-77.

McCAFFREY, K. J. W.; JONES, R. R.; HOLDSWORTH, R. E.; WILSON, R. W.; CLEGG, P.; IMBER, J.; HOLLIMAN, N.; TRINKS, I. Unlocking the Spatial Dimension - Digital Technologies and the Future of Geoscience Fieldwork: Journal of the Geological Society, v. 162, 2005. pp. 927-938.

MENEGUETTE, A. A. C. A. Cartografia no século 21: revisitando conceitos e definições. Revista Geografia e Pesquisa, v. 6, 2013 pp. 6-32.

MENEGUETTE, A. A. C. Geovisualização: exercícios práticos em sala de aula. Revista Brasileira de Cartografia (Impresso), v. 63, 2014. pp. 831-841.

NAPIER, B. GeoVisionary: virtual fieldwork for real geologists. V1 Magazine (http://nora.nerc.ac.uk/13558/), 2011.

SANTOS, J.F.; RIBEIRO FILHO, E. Estratégia de Prospecção Mineral. Bol. IG-USP, Série. didática. n. 2, 1989.

SANTOS, T. C. C.; ANTUNES, M. A. H.; SEOANE, J. C. S.; SOUSA, G. M. Comparison of Atmospheric Correction Models for Worldview-2 Image. Revista Brasileira de Cartografia (Online) v. 69, 2017. pp. 229-240.

SCHEIB, A, J. G. BASE trials of SIGMA digital field data capture: feedback and recommendations. British Geological Survey, 2005. 21p. (Unpublished). 
SEOANE, J. C. S.; OSAKO, L. S.; SILVA FILHO, A. F. Prospecção de Rochas Ornamentais Auxiliada por Sistema de Informação Geo-Referenciada. Revista Brasileira de Geociências, v. 33, n.2, 2003. pp. 73-82.

SHUFELDT, O.; WHITMEYER, S.J.; e BAILEY, C.M. The New Frontier of Interactive, Digital Geologic Maps: Google Earth-Based Multi-Level Maps of Virginia Geology. In Whitmeyer, S.J., De Paor, D.G., Bailey, J., and Ornduff, T. (eds) Google Earth and Virtual Visualizations in Geoscience Education and Research, GSA Special Paper, vol. 492, 2012. pp. 147-164.

SIGEL, H.O. Exploration. Mining Annual Review, vol. 185, 1985 pp. 9-12.

SOUZA FILHO, C. R. e CROSTA, A.P. Geotecnologias aplicadas a Geologia. Revista Brasileira de Geociências, vol. 33, n. 2 (Suplemento), 2003. pp. 1-4.

TERRINGTON, R.; NAPIER, B.; BÜCHI, A.; PROCÓPIO, P, M. Managing the mining cycle using GeoVisionary. Proceedings of $5^{\circ}$ Aachen International Mining Symposia, Aachen, Germany, 2015. pp. 27-28.

WESTHEAD, R.K.; SMITH, M.; SHELLEY, W.A.; PEDLEY, R.C.; NAPIER, B. Mapping the geological space beneath your feet: the journey from 2D paper to 3D digital spatial data. Proceedings of International Conference, London, UK, 2012. pp. 99-102.

WESTHEAD, R.K., SMITH, M.; SHELlEY, W.A., PEDLEY, R.C., FORD, J., NAPIER, B. Mobile spatial mapping and augmented reality applications for environmental geoscience. Journal of Internet Technology and Secured Transactions, vol. 2 2013. pp. 185-190.

WHITMEYER, S. J.; NICOLETTI, J.; DE PAOR, D.G. The digital revolution in geologic mapping. GSA Today, v. 20, n. 4/5, 2010. pp. 4-10.

WHITMEYER, S.J. Community Mapping in Geology Education and Research: How Digital Field Methods Empower Student Creation of Accurate Geologic Maps. In Kastens, K.A., and Manduca, C.A. (eds) Earth and Mind II: A Synthesis of Research on Thinking and Learning in the Geosciences, GSA Special Paper, vol. 486, 2012. pp. 171-174. 